1. DAVID 150 Lumbar/Thoracic Lateral Flexion - боковое сгибание поясничного и грудного отдела позвоночника;

2. DAVID 120 Lumbar/Thoracic Rotation - вращение поясничного и грудного отдела позвоночника;

3. DAVID 1150 Lateral Flexion - боковое сгибание поясничного;

4. DAVID 1110 Back Extension - разгибание поясничного;

5. DAVID 1100 Body Traction- вис на локтях (вытяжение).

В данном клиническом случае метод применим для поддержания и укрепление передне-боковых групп мышц живота, что приводит к стабильности и эффективности методе лечения, что в дальнейшем требует количественную доказательную базу.

$$
* * *
$$

1. Patricia Mota, Augusto Gil Pascoal, Kari Bo, Diastasis Recti Abdominis in Pregnancy and Postpartum Period. Risk Factors, Functional Implications and Resolution, Journal Name: Current Women`s Health Reviews Volume 11, Issue 1, 2015, DOI : 10.2174/157340481101150914201735

2. Boissonnault JS, Blaschak MJ. Incidence of diastasis recti abdominis during the childbearing year. Phys Ther 1988; 68(7):1082-6.

3. Bursch SG. Interrater reliability of diastasis recti abdominis measurement. Phys Ther 1987; 67(7): 10779.

\title{
Казакова А.В., Дуфинец И.Е., Мариновская В.Б. Особенности психических состояний, личностной и реактивной тревожности у женщин с неудачными попытками ЭКО в анамнезе
}

ФГБОУ ВО «Самарский государственный медииинский университет»

doi $10.18411 / g q-31-03-2021-03$

(Россия, Самара)

idsp sciencerussia-31-03-2021-03

\section{Аннотация}

Демографическая ситуация в Российской Федерации в настоящее время не однозначна. Наблюдается снижение репродуктивного потенциала нации, которое определено негативными социальными тенденциями, низким уровнем здоровья женщин репродуктивного возраста. В сложившейся ситуации необходимы централизованные мероприятия, направленные на улучшение репродуктивного пула. Некоторые авторы считают актуальным развитие психологической помощи пациенткам, страдающим бесплодием, в том числе при лечении методом ЭКО. На данном этапе развития клинической медицины, мы наблюдаем, что система психосоциальной помощи женщинам, получающим ЭКО, недостаточно развита. Наше исследование посвящено выявлению особенностей психологических характеристик (психических состояний, личностной и реактивной тревожности) у женщин с неудачными попытками ЭКО в анамнезе. Социологическое исследование проводили методом активного анкетирования женщин по специальным тестам. Уровень реактивной и личностной тревожности определялся по тестам Ханина-Спилбергера. Наличие тревожности и депрессивных реакций на этапе подготовки к лечению должны являться показанием для психологического консультирования.

Ключевые слова: бесплодие, личностная тревожность, реактивная тревожность, психическое состояние, экстракорпоральное оплодотворение

\section{Abstract}

The demographic situation in the Russian Federation is currently mixed. There has been a decline in the reproductive capacity of the nation, which is determined by negative social trends and the low level of health of women of reproductive age. This situation calls for centralized interventions to improve the reproductive pool. Some authors consider it 
necessary to develop psychological assistance for infertility patients, including IVF treatment. At this stage of clinical development, we see that the system of psychosocial care for women receiving IVF is not sufficiently developed. Our research focuses on the identification of psychological characteristics (mental states, personal and reactive anxiety) in women with failed IVF attempts in the history. The sociological study was carried out by means of an active survey of women on special tests. The level of reactive and personal anxiety was determined by the Hanin-Spielberger tests. Anxiety and depressive reactions in preparation for treatment should be an indication for psychological counselling.

Keywords: infertility, personal anxiety, reactive anxiety, mental state, in vitro fertilization

Введение. В двадцать первом веке проблема бесплодия и, связанные с ней проблемы психических расстройств у женщин, крайне актуальны. У пациенток, которые страдают бесплодием, прослеживается негативная тенденция роста тревожных расстройств и депрессивных состояний. Данные Всемирной организации здравоохранения указывают на то, что частота бесплодия в мире составляет 10-15 \% и не имеет тенденции к снижению [1]. Настоящую распространенность бесплодия трудно оценить из-за неоднородности критериев, которые используются для определения бесплодия. Общеизвестно, что проблема бесплодия является клинической, медикосоциальной и социально-психологической. Бесплодие негативно влияет на демографическую ситуацию в стране, часто приводит к конфликтным ситуациям в семьях, психологическому дискомфорту супругов, росту числа разводов. Интерес к изучению психических состояний, личностных особенностей женщин обусловлен тем, что некоторые авторы считают, что психоэмоциональные расстройства можно отнести к патогенетическому звену бесплодия, так как психологические характеристики могут опосредовать стресс, связанный с переживанием бесплодия. Кроме того, они могут лежать в основе психогенных форм бесплодия, предопределять психологические последствия бесплодия, влияющие впоследствии на исход его лечения. Психологические характеристики (психические состояния, личностные особенности) женщин с неудачными попытками ЭКО в анамнезе могут выступать в качестве этиологического фактора развития пограничных психических расстройств, влиять на успешность родов, а также на последующее развитие ребенка. Пациентки с неудачными попытками ЭКО в анамнезе, чаще всего имеют длительный анамнез бесплодия, с этим связано то, что к началу лечения они могут находиться в психоэмоциональном стрессе. Нереализованная репродуктивная функция расценивается женщинами как неполноценность жизни, а это приводит к росту тревоги, формированию депрессии, психосоматической патологии. Именно поэтому психическое состояние пациенток с неудачными попытками ЭКО в анамнезе рассматривается как результирующая часть действия некоторых факторов: соматических, индивидуальных психологических особенностей и генитальной патологии[2,3]. Хотя причины, приводящие к лечению и само ЭКО являются стрессовыми факторами для пациенток, существуют большие индивидуальные различия в психоэмоциональном состоянии у женщин в этот период. В некоторых исследованиях показано, что при увеличении попыток ЭКО, усиливается депрессивная симптоматика, начинают развиваться тревожно-депрессивные расстройства. В тоже время, в других исследованиях не обнаруживаются психологические проблемы, связанные с процедурой ЭКО, а психоэмоциональное напряжение развивается только при реально трудных жизненных ситуаций.

Цель настоящего исследования - выявить особенности психических состояний, личностной и реактивной тревожности у женщин с неудачными попытками ЭКО в анамнезе. 
Материал и методы. В исследовании приняли участие 100 пациенток с диагнозом бесплодие, которые имели более 2 неудачных попыток ЭКО в анамнезе. Эти пациентки составили основную группу. В контрольную группу входили 30 молодых здоровых женщин, которые участвовали в программе «донор яйцеклетки». Возраст пациенток, включенных в основную и контрольную группу варьировал от 21 до 35 лет,

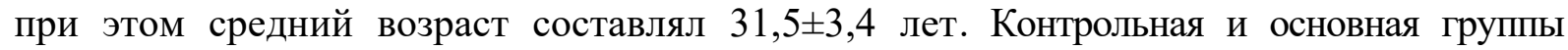
соответствовали по социально-демографическому и возрастному составу. У $36 \%$ женщин длительность наблюдения по проблеме бесплодия ограничивалась двумя годами; 43\% женщин наблюдаются в период от двух до четырех лет; $21 \%$ женщин наблюдаются более четырех лет.

В программу «доноры ооцитов» были включены женщины от 18 до 35 лет; без соматической патологии и психических заболеваний; без вредных заболеваний; имеющих своего здорового ребенка. Претендентки на донорство ооцитов проходят тщательный отбор, тщательное обследование, отправляются на консультации к узкопрофильным специалистам. У данных пациенток исключаются всевозможные инфекции, хронические болезни, психологические расстройства. Из 100 женщин, желающих стать донором, реализовать эту возможность смогла только треть. Это категория абсолютно здоровых людей.

С целью досконального анализа состояния здоровья женщин проводилось комплексное клинико-лабораторное и инструментальное обследование согласно приказу Министерства здравоохранения Российской Федерации от 30 августа 2012 г. №107H

Социологическое исследование проводили методом активного анкетирования женщин по специальным тестам. Уровень личностной (устойчивая характеристика человека) и ситуационной тревожности ( тревожность на текущий момент) определялся по тестам Ханина-Спилбергера. Данный тест представлен в виде опросника из 40 вопросов. Шкала тревожности содержит 20 утверждений, направленных на оценку ситуативной тревожности, и 20 утверждений - личностной тревожности. Тест является надежным источником информации о самооценке уровня своей тревожности в данный момент (реактивная тревожность) и личностной тревожности (как устойчивой характеристики человека). Выделяются три уровня: менее 30- низкий уровень тревожности, 31-45 баллов - средний и более 46 баллов высокий уровень. Тест был разработан Ч.Д. Спилбергером и адаптирован Ю.Л. Ханиным.

Для статистического анализа данных был использован стандартный комплекс прикладных статистических программ Windows. Достоверность различий оценивалась при помощи критерия Стьюдента. Достоверными считались отличия при $p<0,01$.

Результаты и обсуждение. Пациентки из основной группы чаще страдали заболеваниями желудочно-кишечного тракта $(29,3 \%)$, избыточной массой тела и ожирением, чем женщины контрольной группы. Среди заболеваний желудочнокишечного тракта статистически значимые различия касались хронического колита $(9,0 \%)$ и хронического гастрита $(32,7 \%)$. Заболевания ЛОР-органов чаще встречались у женщин «доноров ооцитов», чем у пациенток с бесплодием (54,5\% и 12,2\%), но структура этой патологии была различной. Частота хронического тонзиллита была одинаковой $-27,2 \%$ в основной группе и $28,2 \%$ в контрольной. В целом количество женщин с одним или несколькими очагами хронической инфекции (пиелонефрит, тонзиллит) в контрольной группе составило (57,7\%).

У пациенток с неудачными попытками ЭКО в анамнезе встречались такие формы нарушений менструальной функции, как перименструальное кровомазание $(19,8 \%)$, альгоменорея $(38,5 \%)$.

В анамнезе пациенток основной группы встречались воспалительные заболевания органов малого таза $(59,8 \%)$, миома матки $(18,1 \%)$, наружный генитальный 
эндометриоз $(10,9 \%)$, гиперпластические процессы эндометрия $(9,4 \%)$ и доброкачественные опухоли яичников $(25,7 \%)$. Инфекции, передаваемые половым путем встречались в анамнезе 43,7\%.

Все выявленные в результате клинического, лабораторного и эндоскопического обследования нарушения у' пациенток с неудачными попытками ЭКО в анамнезе были корригированы в процессе подготовки к циклу ЭКО.

Среди женщин, которые были направлены на ЭКО, городскими были 74,0\%, сельскими жительницами $-36,0 \%$. Среди пациенток, прошедших процедуру ЭКО превалировали служащие (77,0\%). Уровень образования: 69,0\% имели высшее образование и $31,0 \%$ - среднее специальное. В зарегистрированном браке состояли $77,0 \%$ женщин, 23,0\% были в гражданском браке. Позволить себе материальные затраты, связанные с проведением программы ЭКО, могут не все женщины. Из всех опрошенных, только 17,0\% имели высокий материальный уровень жизни. Все пациентки проживали в удовлетворительных жилищных условиях. Среди участвовавших в программе ЭКО женщин с низким уровнем жизни и проживавших в плохих жилищных условиях не было.

При изучении самооценки тревожности установлено, что у 93 (94,3\%) пациенток основной группы уровень реактивной тревожности был средним или высоким. В контрольной группе уровень реактивной тревожности у $27(84,4 \%)$ был низким и только у $3(15,6 \%)$ - средним.

Средний показатель реактивной тревожности в основной группе составил $43,88 \pm 1,61$ балла и был статистически достоверно выше соответствующего показателя группы контроля - 32,34 $\pm 0,97$ балла $(\mathrm{p} \leq 0,01)$. Показатель реактивной тревожности является проявлением так называемой эмоциональной реакции на стрессовую ситуацию, что может быть обусловлено психоэмоциональной дезадаптацией пациенток с неудачными попытками ЭКО в анамнезе. При оценке средних показателей уровня

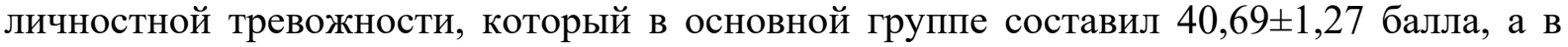
группе контроля - 37,91 $\pm 1,36$ балла, статистически достоверной разницы в группах исследования установлено не было ( $>0,05)$, но при рассмотрении распределения по уровням отмечено, что в основной группе преобладает высокий уровень личностной тревожности $(51,43 \%)$, а в контрольной - средний $(56,25 \%)$.

Учитывая, что более половины пациенток с неудачными попытками ЭКО в анамнезе имеют высокий уровень личностной тревожности, которая является устойчивой индивидуальной характеристикой, отражающей предрасположенность субъекта к тревоге, данный факт следует рассматривать как фактор, способствующий к повторным неудачным попыткам ЭКО.

B исследованиях Bruffaerts R. [4] выделяется, что проявления депрессивных состояний, сопровождающиеся переживанием вины из-за неспособности самостоятельно зачать, чаще встречаются у женщин, нежели у мужчин, и соответственно женщины в большей степени нуждаются в социальной поддержке. В исследованиях Crawford N.M. [5] говорится, что женщины, потерпевшие неудачу в программе ЭКО, при последующих обращениях в программу испытывают депрессивные проявления, они менее удачливы в достижении беременности, чем те, пациентки, которые работали с психотерапевтом или психологом и у них депрессивные проявления нивелировались. Показатели эмоционального состояния женщин были изучены представителями разных школ, и была доказана их взаимосвязь с результативностью и эффективностью лечения бесплодия.

Выводы. Результаты оценки психологического состояния пациенток с неудачными попытками ЭКО в анамнезе показывают выраженную реактивную тревожность в этой группе $(\mathrm{p} \leq 0,01)$, что обусловлено эмоциональной реакцией на 
стрессовую ситуацию и свидетельствует о психоэмоциональной дезадаптации. Учитывая, что более половины пациенток основной группы имеют высокий уровень личностной тревожности, которая является устойчивой индивидуальной характеристикой, отражающей предрасположенность субъекта к тревоге, то данный факт следует рассматривать как фактор риска повторных неудач программ вспомогательных репродуктивных технологий [6].

Наличие тревожности и депрессивных реакций на этапе подготовки к лечению должны являться показанием для психологического консультирования.

Обобщая полученные данные можно сказать, что женщины, прибегающие к лечению бесплодия методом ЭКО, чаще с высоким уровнем образования и удовлетворительными бытовыми условиями.

$$
* * *
$$

1. Бесплодный брак: версии и контраверсии / под ред. В.Е. Радзинского. - М.: ГЭОТАР-Медиа, 2019. -4040 с.: ил.

2. Кулаков В.И., Хритинин Д.Ф., Гарданова Ж.Р., Кулакова Е.В. Тревожно-депрессивные расстройства у женщин в процессе проведения программы экстракорпорального оплодотворения. Вестник Санкт-Петербургской государственной медицинской академии им. И.И. Мечникова № 3 (7). 2016. C.29-35.

3. Наку Е.А., Бохан Т.Г., Ульянич А. Л., Шабаловская М.В., Тосто М.Г., Терехина О.В., Ковас Ю. В. Психологические характеристики женщин, проходящих лечение по программе ЭКО // Вопросы гинекологии, акушерства и перинатологии. 2016. Т. 15, № 6. С. 23-30. DOI: 10.20953/1726-16782016-6-23-30.

4. Bruffaerts R., Enzlin P., Jans I. Gender differences in the experience of infertility. Archives of women's mental health, 2011. Vol.3/4, sup.2. p. 103.

5. Crawford N.M. Infertile women who screen positive for depression are less likely to initiate fertility treatments. Human Reproduction. 2017. Vol.32. No 3. P. 582-587.

6. Казакова А.В., Дуфинец И.Е., Мариновская В.Б., Кияшко И.С. Характеристика личностнопсихологического состояния женщин с неудачными попытками ЭКО в анамнезе. Медикофармацевтический журнал "Пульс" 2020. Vol. 22. N 12 стр. 102-105 http://dx.doi.org/10.26787/nydha-2686-6838-2020-22-12-102-105

\section{Расулов Х.А., Хидирова Г.О., Мусурмонкулов Ж.М., Юсупова Г., Хикматов Ж., Абдуллаева И. \\ Морфофункциональная характеристика трубчатых костей у крыс при гипофункции околощитовидных желёз}

Ташкентский педиатрический медииинский институт (Узбекистан, Ташкент)

doi 10.18411/gq-31-03-2021-04

idsp sciencerussia-31-03-2021-04

\section{Аннотация}

Исследование посвящено к изучению влияния изменений функциональной активности околощитовидных желёз на морфологическую интенсивность формирования костной ткани. Проведено экспериментальное моделирование гипопаратиреоза у лабораторных крыс $(\Pi=30)$ и проанализирована динамика морфологических изменений в процессе окостенения костной ткани. На основе результатов морфологических методов исследования раскрыта динамика формирования трубчатых костей, а также установлены закономерности окостенения костной ткани на фоне гипопаратиреоза. В результате исследования было показано отличие от нормальной гистологической картины гипопаратиреоидных особей в зонах роста, именно базальном слое хондроциты вакуолизированы. Местами определяются появление юных остеобластов, они расположены по типу разнонаправленной архитектоники. 